\title{
A Case of Cutaneous Botryomycosis of the Lower Leg in a Young Adult Male
}

\author{
Fadie Aziz ${ }^{1}$, Ferdinand Ong ${ }^{2}$, Roneil N. Parikh ${ }^{1}$, Auerilius E. Hamilton ${ }^{3}$ \\ 1. General Surgery, Campbelltown Hospital, Sydney, AUS 2. Colorectal Surgery, St. George Hospital, Sydney, AUS 3. \\ Colorectal Surgery, Royal Prince Alfred Hospital, Sydney, AUS
}

Corresponding author: Fadie Aziz, fadieaziz@gmail.com

\begin{abstract}
We present a case of cutaneous botryomycosis of the lower leg in a young adult male. Botryomycosis is a chronic granulomatous response to bacterial infection. As a cutaneous lesion, it can easily be mistaken for a malignant, autoimmune or inflammatory mass. We were able to successfully treat our patient with primary surgical excision, vacuum-assisted closure (V.A.C. ${ }^{\mathrm{TM}}$ ) dressing and subsequent split thickness skin graft (STSG). Use of a V.A.C. dressing with subsequent grafting has not previously been reported in the literature.
\end{abstract}

Categories: Pathology, Plastic Surgery, Other Keywords: botryomycosis, skin graft

\section{Introduction}

We report a case of cutaneous botryomycosis of the leg in a 37-year-old Caucasian male treated with primary surgical excision, vacuum-assisted closure ([V.A.C. $\left.{ }^{\mathrm{TM}}\right]$, KCI-Acelity, San Antonio, TX, USA) and subsequent split-thickness skin grafting (STSG). Botryomycosis is a disease of chronic inflammatory lesions caused by a granulomatous response to bacterial infection [1]. The lesions are often hard and woody, show mixed areas of necrosis, inflammation and suppuration macroscopically and typically elicit a surrounding inflammatory response. The appearance makes it easily mistakable for other malignant, autoimmune or inflammatory lesions, especially since it is not often encountered. Diagnosis may not always be possible with biopsy. If left untreated, these lesions can behave like malignancies, invading into deeper tissues, forming abscesses and having the potential to form fistulas. Features that should alert one to a diagnosis of botryomycosis include rapid growth, response to antibiotics and positive culture on biopsy or swab.

Review began 04/13/2021 Review ended 06/26/2021 Published 07/20/2021

\section{() Copyright 2021}

Aziz et al. This is an open access article distributed under the terms of the Creative Commons Attribution License CC-BY 4.0., which permits unrestricted use, distribution, and reproduction in any medium, provided the original author and source are credited.
With only 200 reported cases in the English literature, botryomycosis is a rare entity. There are no previously reported cases of surgical excision with subsequent use of a V.A.C. dressing and skin grafting and we believe the case presented below shows that this is a suitable reconstructive option.

\section{Case Presentation}

Our patient was a 37-year-old Caucasian male who presented to the emergency department with a 30-day history of a necrotic, ulcerating right calf lesion. He was systemically well and did not have any pain. He denied any preceding trauma or inciting triggers. He had been treated by his general practitioner with oral amoxicillin/clavulanic acid, however, the lesion failed to improve. His past medical history included alcoholism, anxiety disorder, recurrent lower limb cellulitis and a right ankle fracture requiring internal fixation. He was an active smoker with no history of diabetes mellitus. On examination, the $5 \mathrm{~cm}$ diameter lesion had areas of ulceration and necrosis with surrounding cellulitis (Figure 1). There was no clinical evidence of peripheral vascular disease or neuropathy. His white cell count was $11.4 \times 109 / \mathrm{L}$ and his Creactive protein was $6.3 \mathrm{mg} / \mathrm{L}$. An x-ray of his right leg did not show evidence of osteomyelitis. Wound culture grew both methicillin-resistant Staphylococcus aureus (MRSA) and Enterococcus. 


\section{Cureus}

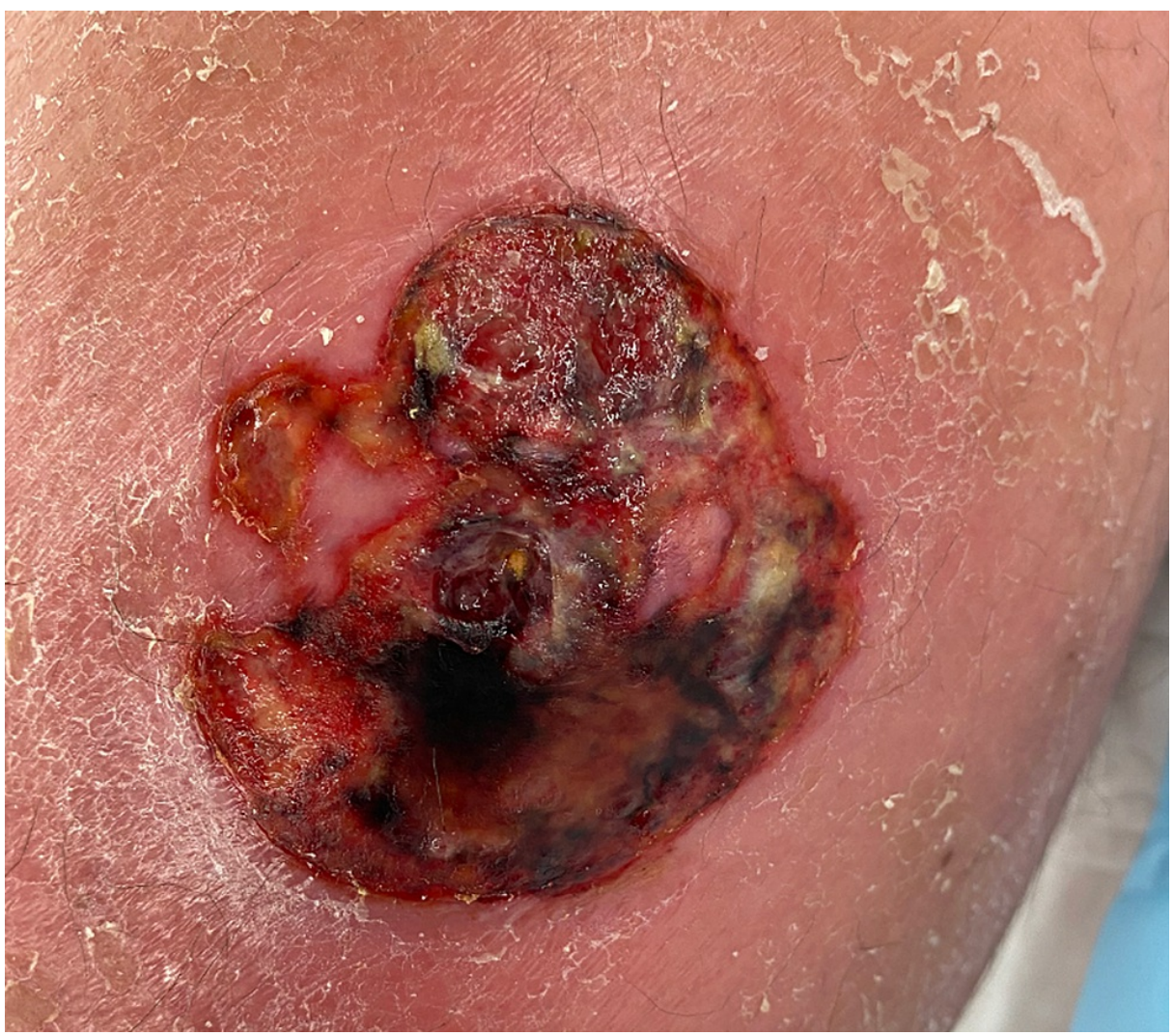

\section{FIGURE 1: Pre-operative photograph of right medial calf lesion showing}

areas of ulceration and necrosis

The patient underwent primary surgical excision of the lesion. Macroscopically, there was low-grade inflammation which is why we delayed grafting. A V.A.C. was applied with negative pressure at $125 \mathrm{mmHg}$ with continuous suction. Histopathology with Periodic acid-Schiff staining revealed extensive suppurative necrosis with fibrosis. The base of the lesion contained granules with blue-stained bacterial organisms surrounded by an intense eosinophilic coat. This finding is in keeping with "Splendore-Hoeppli Phenomenon", a finding characteristic of botryomycosis. There was no evidence of malignancy and no fungal organisms were identified. He was treated with 48 hours of intra-venous clindamycin and discharged with a two-week course of oral clindamycin as guided by the infectious diseases team. The V.A.C. was managed by community nurses.

Upon review in the clinic, the wound bed appeared healthy with good granulation tissue. The cellulitis had improved (Figure 2). 


\section{Cureus}

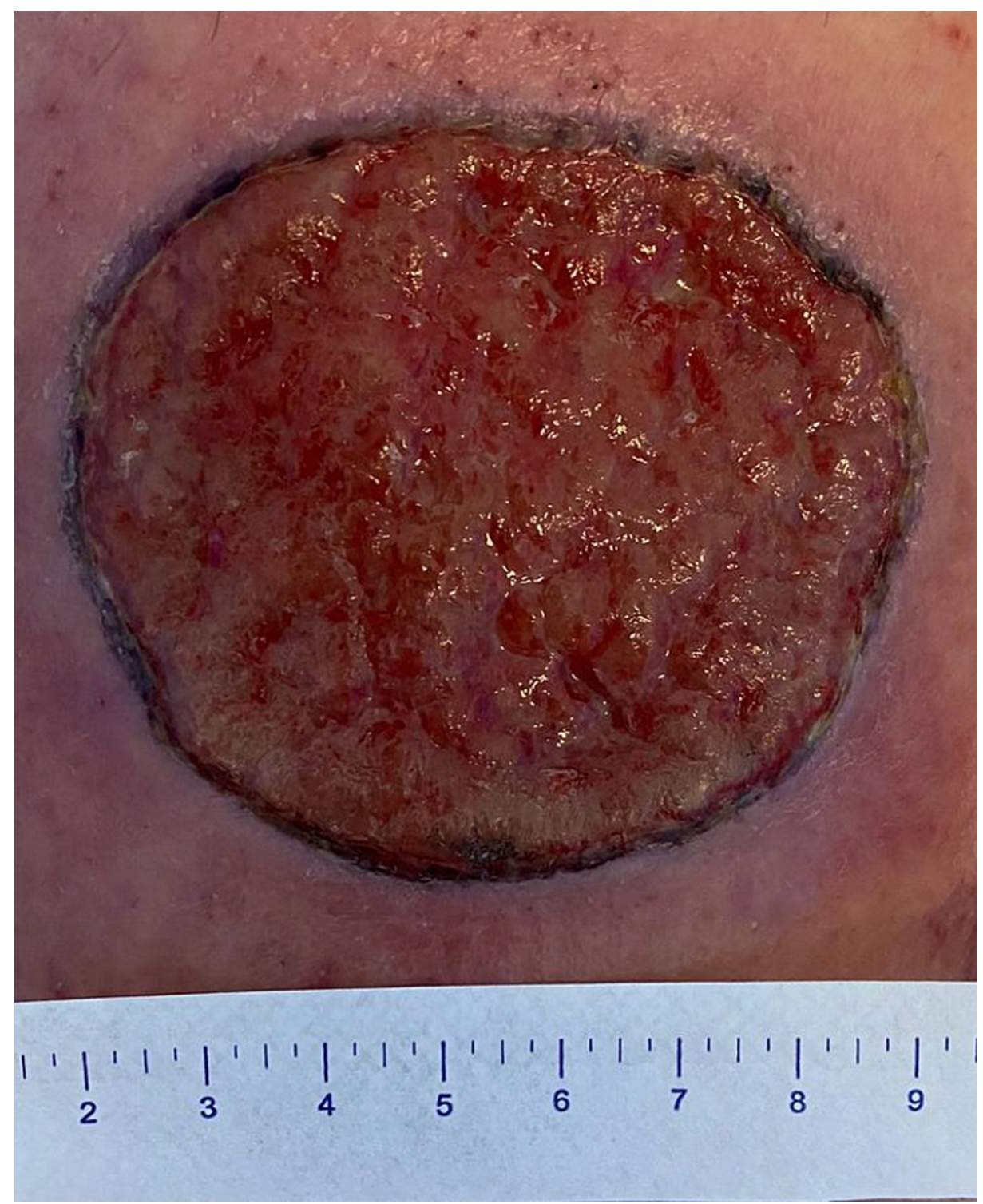

FIGURE 2: Wound bed on day 30 post excision

The patient's V.A.C. dressing was only attended to in clinic due to anxiety surrounding changing these dressings at home. Once the inflammation settled and the wound base appeared healthy, the patient was readmitted and underwent a split-thickness skin grafting procedure. Upon follow-up, the graft took well (Figure 3). 


\section{Cureus}

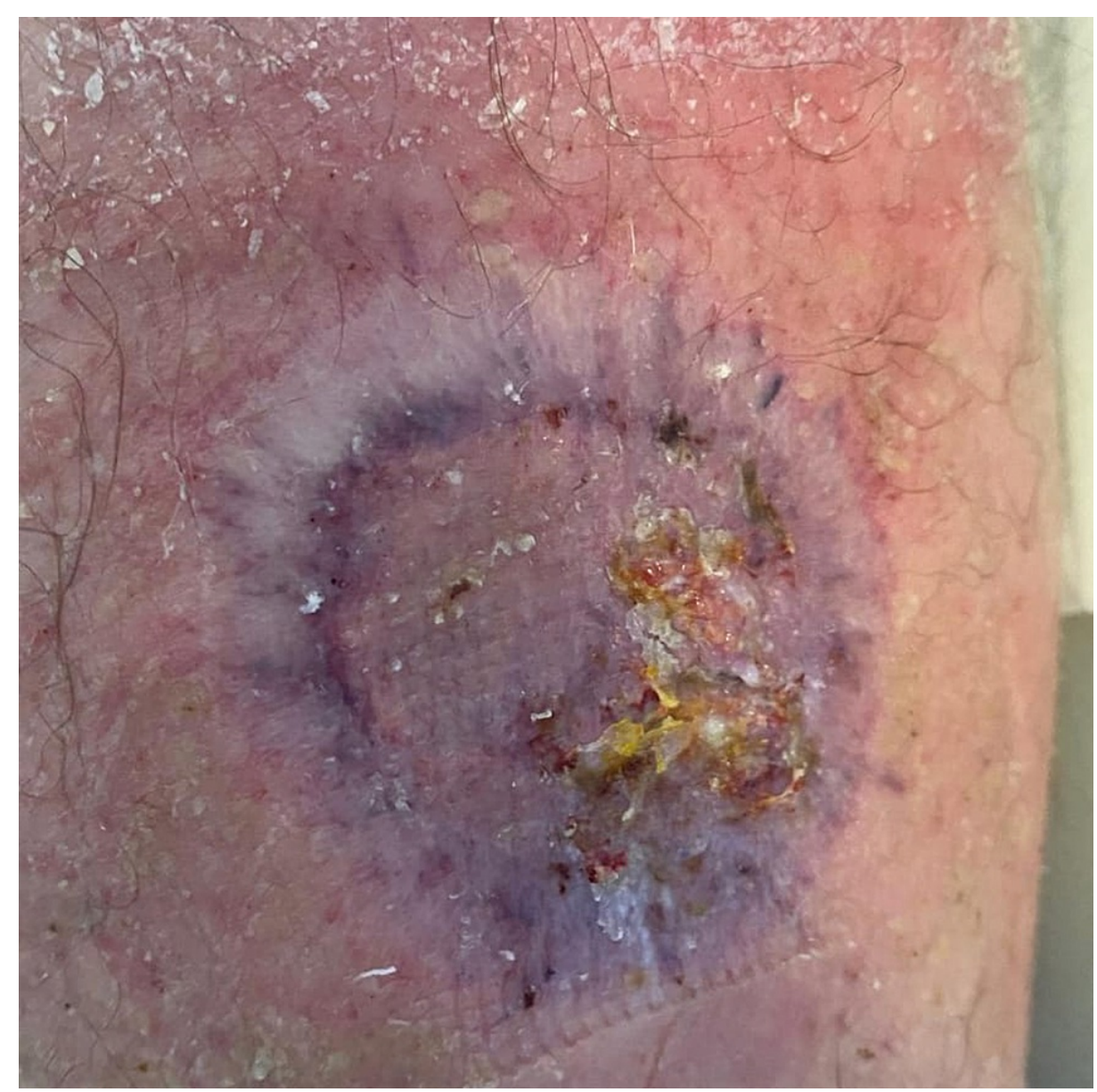

FIGURE 3: Grafted wound

Discussion

Botryomycosis may be either cutaneous (75\% of cases) or visceral, typically affecting the lungs but possibly involving the liver, spleen, brain or kidneys [2]. Its name derives from the Greek "botryose" meaning cluster of grapes and "mycosis" referring to the original perception that it was caused by fungi. This name refers to the characteristic histopathological finding of granules containing bacteria surrounded by an eosinophilic zone; the so-called "Splendore-Hoeppli Phenomenon" (SHP). Whilst characteristic, this finding is not pathognomonic and may be seen in actinomycosis as well as fungal and helminthic infection [3].

The most frequently implicated organism is Staphylococcus aureus (40\% of cases) followed by Pseudomonas aeruginosa (20\% of cases) and Escherichia coli. Other implicated organisms include Proteus and Streptococcus species [2]. Cutaneous botryomycosis has an insidious onset and is thought to arise from an inoculating trauma and therefore is usually found to affect the head, neck, and extremities. It can manifest as nodules, non-healing ulcers, sinuses or fistulae and has the potential to invade deeper. Predisposing factors include alcoholism, diabetes mellitus, immunosuppression, and malnutrition [4].

Botryomycosis is thought to arise when there is a balance between the virulence of the involved bacteria, the size of inoculum and an impaired host response. Too little inoculum, low bacterial virulence and a robust host response favours clearance of the infection. In the opposite scenario, bacterial infection overwhelms the host response forming an abscess [5]. Microscopically, this balance manifests as the SHP, whereby antigenantibody complexes and fibrin form an eosinophilic coat that surrounds bacterial granules and prevents phagocytosis [6].

There are reported cases of successful management with antibiotics exclusively, however combination with surgical debridement is often used $[7,8]$. In our case, we elected for antibiotic therapy with surgical excision and subsequent STSG given the size and location of the lesion and the presence of macroscopic necrosis. Use of an STSG has been reported twice previously in the literature with one of the grafts failing $[4,9]$. Use of a V.A.C. dressing with subsequent STSG once the infection resolved has not been previously published.

\section{Conclusions}


In conclusion, this rare clinical entity may easily be mistaken for a malignant lesion, or a non-infective inflammatory or autoimmune mass. In cases where lesions are smaller and not yet necrotic, primary antibiotic therapy would be feasible. However, larger lesions will most likely be non-responsive due to a lack of antibiotic penetrance and the presence of necrotic tissue requiring debridement. Our case highlights that surgical excision and V.A.C. dressing allow time to treat the infection. An STSG is a suitable reconstructive option.

\section{Additional Information \\ Disclosures}

Human subjects: Consent was obtained or waived by all participants in this study. Conflicts of interest: In compliance with the ICMJE uniform disclosure form, all authors declare the following: Payment/services info: All authors have declared that no financial support was received from any organization for the submitted work. Financial relationships: All authors have declared that they have no financial relationships at present or within the previous three years with any organizations that might have an interest in the submitted work. Other relationships: All authors have declared that there are no other relationships or activities that could appear to have influenced the submitted work.

\section{References}

1. Mechow N, Göppner D, Franke I, Kolesnik M, Bonnekoh B, Gollnick HP, Quist SR: Cutaneous botryomycosis diagnosed long after an arm injury. J Am Acad Dermatol. 2014, 71:e155-6. 10.1016/j.jaad.2014.06.017

2. Padilla-Desgarennes C, Vázquez-González D, Bonifaz A: Botryomycosis. Clin Dermatol. 2012, 30:397-402. 10.1016/i.clindermatol.2011.09.010

3. Yencha MW, Walker CW, Karakla DW, Simko EJ: Cutaneous botryomycosis of the cervicofacial region. Head Neck. 2001, 23:594-8. 10.1002/hed.1083

4. Karthikeyan K, Thappa DM, Jeevankumar B: Cutaneous botryomycosis in an agricultural worker. Clin Exp Dermatol. 2001, 26:456-7. 10.1046/j.1365-2230.2001.00857-2.x

5. Gehlhausen J, Strausburg MB, Gilbert KE, Alomari AK: Early botryomycosis-like plaques in the setting of Corynebacterium striatum septicemia. Int J Dermatol. 2019, 58:969-71. 10.1111/ijd.14162

6. John K, Gunasekaran K, Kodiatte TA, Iyyadurai R: Cutaneous botryomycosis of the foot: a case report and review of literature. Indian J Med Microbiol. 2018, 36:447-9. 10.4103/ijmm.IJMM_18_347

7. Vasishta RK, Gupta N, Kakkar N: Botryomycosis--a series of six integumentary or visceral cases from India . Ann Trop Med Parasitol. 2004, 98:623-9. 10.1179/000349804225021280

8. Askari K, Seyed Saadat SN, Seyed Saadat SM, Yousefi N, Ghorbani G, Zargari O: Cutaneous botryomycosis caused by Staphylococcus aureus in a patient with diabetes. Int J Dermatol. 2014, 53:413-5. 10.1111/ijd.12325

9. DeWitt JP, Stetson CL, Thomas KL, Carroll BJ: Extensive cutaneous botryomycosis with subsequent development of nocardia-positive wound cultures. J Cutan Med Surg. 2018, 22:344-6. $10.1177 / 1203475418755762$ 